\title{
Traços da perambulação no Cinema Marginal'
}

\author{
Fábio Raddi Uchôa
}

\section{Apresentação}

pesar de autores como Ismail Xavier (2001b) e Jean-Claude Bernardet (2001)
indicarem portas de entrada para o exame da perambulação no contexto do
Cinema Marginal, até o momento não existe um estudo sistemático sobre o assunto. É neste âmbito que se insere a pesquisa aqui resumida, com o intuito de colaborar com um esboço de abordagem, levando em conta o cotejo com a conjuntura artístico-cinematográfica, bem como a definição da noção de perambulação, na qualidade de um fenômeno que associa reverberações objetivas e quanto à situação das personagens, unindo traços de colagem transgressora e pessimismo ante ao panorama político, bem como a sugestão de quatro chaves para o questionamento de filmes do período.

\section{O contexto do Cinema Marginal}

A partir de 1968, com a promulgação do AI-5 (Ato institucional n. 5), o fechamento do congresso e o intensificar das perseguições políticas, há um aprofundamento da crise democrática que, somado às reverberações da contracultura tropicalista e a fatores de ordem de produção cinematográfica, influenciaria na radicalização estética do Cinema Marginal - grupo heterogêneo de obras e expoentes que terá desdobramentos em diversas regiões da Brasil, porém com maior concentração em São Paulo e Rio de Janeiro. Em sua vertente paulista, do cinema do lixo (Gomes, 1980: 97) e do cinema cafajeste (Callegaro, 1968), trata-se de um grupo de cineas- 
tas e críticos - entre eles, Ozualdo Candeias, Jairo Ferreira, Carlos Reichenbach, Rogério Sganzerla, José Agrippino de Paula, João Batista de Andrade e João Callegaro - concentrados na Boca do Lixo. A partir do final da década de 1960, devido a uma confluência de fatores culturais e quanto à política cinematográfica, tal região, situada no bairro da Luz, se consolidaria como polo produtor de comédias eróticas, gênero de produção rápida, com apelo sexual e envolvendo contatos diretos entre produtores e exibidores (Abreu, 2006). A deflagração do movimento é atribuída a $A$ margem (1967), de Candeias, com seu gosto pelo lixo e pela marginalidade urbana, bem como a O bandido da Luz Vermelha (1968), de Saganzerla, com sua tendência ao deboche e à fusão tropicalista de fragmentos culturais. Em contato com atores e técnicos, aproveitando-se eventualmente de alguns dos elos da cadeia de produção cinematográfica da Boca do Lixo paulista, os cineastas marginais colaboram para o advento de um grupo variado de filmes, marcado pela violência estética, a consciência da incapacidade de intervenção política num país em estado de exceção, assim como por um reprocessar politizado da indústria cultural importada, com uma colagem por vezes irônica e debochada.

Na vertente carioca, organizada em torno da produtora Belair, Júlio Bressane e Rogério Sganzerla realizarão sete obras em apenas quatro meses de trabalho, apresentando grande sintonia estilística. Filmes como A família do barulho (1970), Copacabana mon amour (1970) e Sem essa aranha (1970), são marcados por ações repetitivas e rarefeitas, planos prolongados, a multiplicação de referências à chanchada e aos gêneros cinematográficos estrangeiros e o metacinema. Algumas dessas obras são finalizadas pelos cineastas no exílio; ou seja, trata-se de filmes que incorporam, no estilo e no próprio processo de realização, os deslocamentos ao exílio em decorrência da repressão militar.

A partir dos traços de interesse presentes nos estudos clássicos sobre o assunto, algumas características da produção marginal podem ser destacadas. Para Fernão Ramos de Cinema Marginal (1968-73), tais obras compartilham a curtição, o grotesco e a fragmentação narrativa, bem como uma relação agressiva com o espectador, com o uso de imagens abjetas (vômitos, animalização do ser humano, deglutição aversiva, etc.) que, associadas ao horror, interferem na fruição e no desenvolvimento linear das ações. Define também um período de concentração para a produção marginal: 1968-1973. Para Ismail Xavier, os filmes destes cineastas realizam uma "resposta à repressão na linha agressiva do desencanto radical; sua rebeldia elimina qualquer dimensão utópica e se desdobra na encenação escatológica, feita de vômitos, gritos e sangue, na exacerbação do kitsch" (Xavier, 2001a: 76). Pensados no contexto mais amplo do impasse político de 1968, Ismail Xavier sugere que tais filmes colaboram para sintetizar o reconhecimento do descompasso, entre as expectativas e a realidade, prestando-se à internalização da crise e à conscientização do subdesenvolvimento como horizonte. Assim, em Alegorias do subdesenvolvimento, ao pensar no cinema do 
período a partir do recurso à alegoria da situação nacional, incluindo a dialética entre totalização e fragmentação, Xavier refere-se ao Cinema Marginal a partir deste segundo polo: conjunto de obras marcadas pela antiteleologia, seja em termos de ataque à continuidade narrativa clássica, seja enquanto embaçar do diagnóstico da experiência nacional. No contexto da modernização conservadora levada a cabo pelo governo militar, há um rápido avanço da indústria cultural, que terá reverberações no Cinema Marginal e sua abertura irônica à cultura industrial estrangeira.

Em termos estilísticos e temáticos, os filmes do Cinema Marginal reverberam uma colagem em parte sintônica com o Tropicalismo, movimento com presença marcante na música, no teatro, nas artes plásticas e no cinema a partir de 1968. Tratamos assim de gestos que incluem o jogo de contaminações (nacional/estrangeiro, alto/ baixo, vanguarda/kitsch), a colagem do diverso, a reapropriação da cultura importada a partir de corações locais (Xavier, 1993). Ao definir o Tropicalismo do contexto dos anos 1967-68, Roberto Schwarz (1992) indica uma articulação de conteúdos e linguagens, entre o arcaico e o moderno, com a capacidade de unir o grotesco e o ultramoderno colocando-os como alegoria do país. Celso Favaretto, por sua vez, refere-se ao movimento a partir da função crítica da obra de arte, associada ao cotejo de elementos da indústria cultural e de materiais tradicionais brasileiros. Por meio da colagem de cacos das culturas brasileira e internacional, as contradições próprias ao país eram metamorfoseadas e incorporadas à estrutura das obras (Favaretto, 1979). No contexto do cinema, pode-se pensar que o gestual artístico tropicalista incorpora traços de carnavalização (Bentes, 2007), releituras da deglutição antropofágica dos anos 1920 sob o viés de um cinema antropofágico (Ramos, 2009), vinculando-se também a estéticas híbridas e multitemporais (Stam, 2010).

Somando-se à colagem tropicalista e reverberando os traços acima descritos, no cinema moderno brasileiro há uma recorrência de figuras de perambulação: grandes viagens em busca do país que se perdia, ou então deslocamentos realizados como válvula de escape transgressor - flertando com o caleidoscópio temático-formal tropicalista e internalizando a violência e o desespero. Em "Cinema Marginal?” Jean-Claude Bernardet identifica a perambulação como traço comum ao Cinema Novo e ao Cinema Marginal. Em alguns filmes, os deslocamentos assumem a metáfora de uma viagem pelo país, onde importa muito mais o trajeto do que a partida ou a chegada. Em outros filmes a perambulação é apenas uma arte do deslocamento pedestre ou automotivo.

Anda-se muito nestes filmes, e andar nem sempre é fácil: os sapatos machucam ou a ferida na perna dói. Aliás, não só nestes filmes se anda. (...) A deambulação foi retomada pelo Cinema Novo, desde Porto das Caixas e Os Cafajestes, e pelo Cinema Marginal. Quando vários personagens deslocam-se um atrás do outro, forma-se um cortejo. Essa forma foi também apreciada nos anos 50-60: Cinzas 
e diamantes, La Dolce Vita, com ecos no cinema Brasileiro, e Fome de Amor, por exemplo, e evidentemente Orgia, filme de deambulação por excelência, em que o grupo vai se formando e organiza-se de modo paulatino num cortejo. A deambulação, tradicional arte pedestre, pode ser automotiva: O desafio, Vida de artista e seus planos de carros celebrados por Jairo Ferreira; os inesquecíveis planos de Bang-bang pelas avenidas de Belo Horizonte. Essa arte do travelling sem corte estica o tempo num espaço em continuidade (Bernardet, 2001: 14).

Paulo Emílio Salles Gomes, por sua vez, referindo-se aos marginais paulistas, destaca a eloquência da abordagem:

Conglomerado heterogêneo de artistas nervosos da cidade e de artesãos do subúrbio, o Lixo propõe um anarquismo sem qualquer rigor ou cultura anárquica e tende a transformar a plebe em ralé, o ocupado em lixo. Este submundo degradado percorrido por cortejos grotescos, condenado ao absurdo, mutilado pelo crime, pelo sexo e pelo trabalho escravo, sem esperança ou contaminado pela falácia, é porém animado e remido por uma inarticulada cólera (Gomes, 1980: 97, grifo nosso).

Diante do recrudescimento do regime militar, os deslocamentos presentes em tais obras possuem uma importância dupla: por um lado, reverberam a colagem tropicalista, unindo cacos do moderno e do arcaico de maneira alegórica; por outro, representam a impotência, a agonia e a falta de saídas diante da conjuntura. "A perambulação, típica do cinema moderno, atingiu em sua versão marginal uma feição mais radical, afinada ao senso de ultrapassar limites, cortar amarras, como uma metáfora ao próprio gesto dos cineastas" (Xavier, 2001b: 21).

\section{A questão da perambulação: aporte físico}

A perambulação consiste numa oposição à narrativa do cinema clássico, presente no cinema de vanguarda dos anos 1920 e retomada, a partir do final dos anos 1940, pelo neo-realismo e os cinemas novos. O andar a esmo e sem destino, pedestre ou automotivo, subverte a noção clássica de personagem, bem como a própria ideia de narrativa, caracterizada por uma cadeia de eventos relacionados em termos de causa e efeito. No cinema moderno, "o ponto decisivo é a 'poeira' que se levanta no caminho, a força de cada episódio, o que há de revelador em cada instante de vida (...) o esgarçamento da narrativa, a perambulação, os impasses, a impotência da ação, ativando uma sensibilidade ao fragmento, ao que se esboça mas não termina" (Xavier, 2003: 226).

Entre os filmes neo-realistas, com seus personagens que perambulam pela Itália da guerra e do pós-guerra, o caminhar a esmo será recorrente. Em seus escritos 
sobre o movimento cinematográfico italiano, especialmente em Rossellini, Bazin (1985) ressalta uma câmera atenta aos fatos. Em alguns momentos de Paisà (1946), a câmera limita-se a seguir os personagens, como que numa reportagem imparcial, com o cuidado de apenas estar com eles, compreendendo-os e sofrendo com eles. É assim que a câmera acompanha, em Alemanha, ano zero (1948), numa sequência de mais de 10 minutos, a marcha de um garoto para a morte. Não se pressupõe que o personagem se suicidará; nem se exige do espectador que ele realize tal interpretação; apenas o gesto final, o suicídio, proverá a chave interpretativa, a posteriori. Para Bazin, Rossellini

(...) só encena os fatos. (...) Seus personagens estão como que assombrados pelo demônio da mobilidade. (...) O universo rosselliniano é um universo de atos puros, insignificantes neles mesmos, mas que preparam, quase que sem que Deus mesmo se dê conta, a revelação repentina e deslumbrante de seu sentido. (...) (Bazin, 1985: 355).

A partir dos comentários de Bazin acerca de Rossellini, pode-se pensar na perambulação como evento físico, que se opõe à dramatização e ao tratamento psicológico existentes no cinema clássico. Há, porém, uma espécie de revelação (de uma consciência de mundo, do sofrimento humano e do humanismo), presenciada pelo espectador a posteriori.

A ideia de perambulação, por meio do termo "deambulação"2, será reavaliada pelos críticos-cineastas da Nouvelle Vague. Como explicitado Jean Douchet (1999), o grupo de jovens cineastas era influenciado por André Bazin e, também, pela retomada de cineastas como Rossellini. A Nouvelle Vague seria então um cinema marcado pela linguagem do corpo - o que implica na transformação do espaço e da gestualidade - e por um espaço "entregue ao presente do acontecimento, registrado por uma câmera de atualidade, sofrido pelas personagens e observado pelo espectador, testemunha do acidente." Em tal contexto, as personagens "já não têm, (...) o controle físico do seu comportamento, perderam-lhe o objetivo, entraram numa espécie de errância." (Douchet, 1999b: 174) Segundo o crítico francês, "Tratar-se-á de um cinema físico onde a deambulação se torna o próprio centro de interesse (...)" (Douchet, 1999b: 174); um cinema onde a "busca pela exatidão de um gesto ou postura" e a "pesquisa de verdade no e pelo corpo" serão cruciais.

\section{A questão da perambulação: aporte físico-mental}

Em $A$ imagem-movimento, Deleuze define a perambulação como um dos traços que se afirmariam no cinema do pós-guerra, na senda daquilo que concebe como crise da imagem-ação - originalmente caracterizada por ações fundadas no enca- 
deamento sensório-motor e dados espaço-temporais bem definidos. Em oposição ao domínio da intriga, da ação e dos laços de causa e efeito, o pós-guerra italiano abrirá espaço para filmes onde: a imagem remete-se a uma situação dispersiva, os encadeamentos e ligações são propositalmente fracos, o acaso coloca-se como fio condutor e a coesão é mantida por um conjunto de clichês externos e psíquicos. Investe-se na potência do falso, incluindo a própria dissolução do espaço enquanto variável estável:

Com efeito, isso é o que há de mais notório na perambulação moderna, o fato de ela se dar num espaço qualquer, estação de triagem, entreposto abandonado, tecido desdiferenciado da cidade, em oposição à ação que no mais das vezes se desenrolava nos espaços-tempos qualificados do antigo realismo. Como afirma Cassavetes, trata-se de desfazer o espaço, tanto quanto a história, a intriga ou a ação (Deleuze, 1985: 234).

Tal oposição à imagem-ação, para Deleuze, realiza-se num contexto que sucede diretamente ao trabalho de Hitchcock, cineasta que teria pela primeira vez, introduzido a imagem mental no cinema, num trabalho que seria retomado pelo neo-realismo. Neste último caso, tal crise relaciona-se ao velamento das coordenadas espaciais e da emergência dos "lugares quaisquer, onde se desenvolviam os afetos modernos de medo, de desapego, mas também de frescor, de velocidade extrema e de espera interminável” (Deleuze, 1985: 142). Entre o pós-guerra e os anos 1950, a perambulação faz parte de um tipo de cinema dominado por clichês interiores e exteriores, próprios a uma realidade dispersiva e lacunar, "imagens flutuantes, (...) clichês anônimos que circulam num mundo exterior, mas também penetram em cada um e constituem seu mundo interior (...) (Deleuze, 1985: 234). Não é gratuita a inserção deleuziana da perambulação num contexto onde a imagem é dotada de traços internos e externos, objetivos e subjetivos, aproximando-se da ambiguidade típica do estilo indireto livre pasoliniano. Em Empirismo eretico, o poeta e cineasta pensa o cinema moderno a partir da ideia de Cinema de Poesia, marcado por contaminações entre narrativa e personagens, onde as operações próprias ao cinema moderno, que incluem a construção física dos travellings e da perambulação, articulam-se à expressão do mundo interior de personagens enlouquecidas ou em descompasso ante ao mundo. Os traços narrativos, extremamente objetivos, sugerem estados psicológicos da alma, predominantes ao longo dos filmes e próprios a heróis anormais.

Pensar a perambulação no contexto de um aporte físico-mental, na esteira de Deleuze e Pasolini, nos remete também à produção crítica de Rogério Sganzerla, que em Por um cinema sem limite sugere a existência de duas vertentes que podem mesclar-se de diferentes maneiras no cinema moderno: os cineastas do corpo e os cineastas da alma. Por um lado, um cinema físico, do presente e das aparências, 
próximo às concepções da pop-art e baseado na apreensão direta dos corpos em conflito com o mundo; por outro lado, o cinema dos movimentos, profundidades e conflitos interiores do homem (Sganzerla, 2001: 89).

\section{Chaves da perambulação no Cinema Marginal: esboço para um mapeamento}

Nos filmes do Cinema Marginal, os traços de perambulação, por vezes restritos a passagens pontuais, colaboram para a construção de lógicas narrativas mais amplas. Os travellings, as panorâmicas e os enquadramentos que oprimem a presença dos corpos reduzindo-os a objetos passivos em deslocamento, a montagem que associa espaços díspares ou em fluxo constante, bem como a simples ênfase ao caminhar pedestre ou automotivo, são meios técnicos para a construção da perambulação física. Eles se inserem em narrativas rarefeitas, marcadas pelo desespero e pela incompletude. Num cinema onde o próprio relato assume traços ambíguos e autônomos, a perambulação possui traços objetivos e subjetivos, associando-se à própria experiência de personagens em crise. Para uma proposta inicial de mapeamento, levando-se em conta as formulações físicas, os contextos temáticos e a situação dos personagens, pode-se identificar quatro chaves de abordagem, que apesar de apresentadas separadamente, possuem pontos de interseção, podendo coexistir numa mesma obra.

\section{Perambulações automotivas}

Definição geral: deslocamentos urbanos ou rurais, realizados em automóveis, tendo o travelling rijo e linear como técnica narrativa recorrente. Entre outras influências, a reapropriação de gêneros flerta com os cinemas noir e de gangster, com sua tendência às perseguições automotivas, algumas delas noturnas, e o gosto pelo status dos calhambeques. Trata-se de uma tendência revisitada, ao longo dos anos 1960-70, por cineastas como Rogério Sganzerla e Andrea Tonacci, em cujos filmes os deslocamentos físicos colaboram para narrativas marcadas pelo embaralhar, a repetição neurótica e a não-conclusão. Enquanto a situação clássica de perseguição envolve as relações entre o perseguidor e o perseguido, contendo possíveis obstáculos para a finalização da ação, nos filmes de Sganzerla e Tonacci presenciamos diferentes modos de rarefação e ironia à existência de tal bipolaridade: muitas vezes, persegue-se sem saber o quê; ou então, há uma dissolução da situação de perseguição espacial, que é internalizada na forma de um sentimento obsessivo. ${ }^{3}$

Olho por olho (1966), de Andrea Tonacci, exibido no contexto do Festival de Cinema JB-Mesbla, é um curta-metragem realizado em São Paulo, que se configura como pura perambulação automotiva, precedendo o gosto pelos deslocamentos urba- 
nos próprios ao Cinema Marginal. Um grupo de jovens circula pelo centro da capital, aparentemente sem motivações ou objetivos; no final, descobre-se a sua ação como um grupo criminoso, que violenta a vítima, como se a violência física e gratuita pudesse suprir a impotência dos personagens diante de um país dominado por elites militares e conservadoras. Destacam-se os deslocamentos físicos, bem como o estiramento do espaço urbano, formulados a partir da arte do travelling que, na última sequência, abandona os personagens num movimento reverso, embebido pela incapacidade de ação e de intervenção no curso da história. Enquanto figura física, temos uma perseguição em gangue, cujo objetivo é revelado apenas no final. Os personagens, por sua vez, são tomados por uma curtição urbana com toques de cinismo e impotência.

Em Bang-Bang (1971), também de Tonacci, nota-se uma maturação da perambulação automotiva iniciada em Olho por olho. $\mathrm{Na}$ construção das personagens e do relato do filme, ganham destaque as ações inconclusas. O núcleo de protagonistas é formado por uma gangue de impotentes: um cego, uma velhinha e um parasita indiferente, que se deslocam pelas avenidas de Belo Horizonte e por estradas desertas. Em termos físicos, notamos longos travellings de avenidas e estradas, compondo perseguições sem finalidade; por vezes, em detrimento da presença dos personagens, ganham destaque as paisagens e horizontes vazios. A experiência com o travelling feito com a câmera no banco de trás do carro ganha densidade. Destaque ao longo plano-sequência, repetido no início e no meio do filme, onde um dos personagens pega um táxi e a viagem torna-se uma briga com o condutor, que não consegue engatar a terceira marcha, recaindo num cíclico reinício da aceleração. A articulação de travellings e planos-sequência, por sua vez, sugere um cadeia de ações sem desdobramentos e com repetições neuróticas: um câmbio automotivo avariado que falha no engate. Temos assim perseguições sempre recomeçadas, associadas a uma neurose da incapacidade de conclusão.

Em O bandido da Luz Vermelha, de Rogério Sganzerla, a perambulação automotiva pontua apenas algumas das sequências: no início a perseguição policial pela Boca do Lixo, retomando variações da câmera colocada dentro do carro, em tomadas noturnas; mais adiante, a viagem para a Baixada Santista, demarcando um itinerário onde a presença do automóvel em São Paulo e depois na praia, com a junção de espaços por meio da montagem, sugere a realização do deslocamento. Em alguns momentos, na própria areia da praia, o perambular automotivo sem rumos que por vezes é substituído por gravitações da câmera em torno do carro. O deslocamento automotivo é apenas uma peça, dentro de uma estrutura caleidoscópica mais ampla, onde a profusão de espaços, gêneros cinematográficos e identidades mimetizam a personalidade de um bandido em crise; personagem cuja trajetória corresponde à busca por si e à tentativa de suicídio.

Em Abismu (1977), também de Sganzerla, a perambulação de Madame Zero com um enorme charuto na boca, dirigindo um Cadilac na serra do mar, assume

\footnotetext{
164 ALCEU - n.33 - jul./dez. 2016
} 
o status de uma viagem intersideral, que corresponde à nulidade do poder da personagem e, ao mesmo tempo, à explosão do planeta Terra. Trata-se de uma busca mística pelo ouro universal, a partir de mapas em hieróglifos, numa aventura onde o movimento em direção ao Pão de Açúcar é comparável a um movimento temporal, em direção aos maias, aos astecas e aos povos egípcios; movimento que une cabala, zen-budismo e umbanda, num espaço que é, ao mesmo tempo, o Rio de Janeiro, o Caribe, a América, o terceiro mundo e o universo sideral. Os travellings e planos do carro em movimento, a partir de um jogo fragmentado de associações de formas, aproximam o perfil da personagem ao busto de uma esfinge e ao ornamento do capô do carro - objeto americano resplandecente, típico do cinema noir; objeto de montagem pop, que desliza por uma paisagem tropical. Os movimentos do carro, portanto, tomam parte neste jogo proposto pelo relato, que trabalhará com a disjunção, a repetição e a associação de certas formas/fisionomias, incluindo uma multiplicação pop das identidades dos personagens.

\section{Perambulações pedestres}

Definição geral: deslocamentos pedestres, individuais ou em grupo, tendo o nervosismo dos travellings e dos movimentos de câmera entre os principais traços narrativos. As relações entre as tremulações fotográficas e a enunciação de si por parte dos personagens em desespero são mais evidentes. Entram em questão, especialmente, os travellings reversos e as tensões entre câmera e personagens em meio aos transeuntes. Em termos temáticos, notam-se figuras da perseguição militar, do caminhar pedestre como projeção da tortura psicológica, mas também deslocamentos em busca do próprio país, seja ele ironicamente relegado à sífilis ou a um estado de sítio militar. ${ }^{4}$

Gamal, o delírio do sexo (1969), de João Batista de Andrade, é pura perambulação atordoada, a partir dos remorsos físicos e psíquicos de um jornalista perseguido. A tortura psicológica desdobra-se numa busca desenfreada pelo sexo, na duplicação dos gestos, movimentos e personagens, bem como na violência das disjunções sonoras. Torturado pelo ambiente de trabalho, Jorge exercita uma fuga alucinada pelo centro e pelos subúrbios de São Paulo. Sua trajetória é violenta - a partir de nervosos travellings ou movimentos de câmera, as perambulações figuram a perseguição e a impotência física e mental. Duas formulações podem ser destacadas: primeiro, os travellings reversos, com a tensão do personagem que avança em direção à câmera, numa busca que não é física e sim interior; segundo, as tensões entre a câmera e os personagens em deslocamento pelas ruas, com um cinema de rua que cria happenings através da atuação dos atores-personagens desesperados em meio aos transeuntes. Em uma das sequências pela Praça da República, a narrativa adere aos surtos psicóticos de Jorge; a experiência de loucura é explicitada pelo relato: panorâmicas 
vorazes sugerem embriaguês; as interações dos personagens entre si, com a multidão ou com os carros simulam a experiência do corpo fisicamente detido ou barrado. Pode-se pensar, assim, numa performance-impotência, onde o contato com a multidão é reproduzido em termos da desorientação e da retenção, organizado numa longa sequência marcada pelo "dilaceramento dramático" e pela "expressão de uma agonia absoluta" (Ramos, 1987: 85).

Considerado por Jean-Claude Bernardet como um filme de deambulação por excelência (Bernardet, 2001: 14.), Orgia ou o homem que deu cria (1970), de João Silvério Trevisan, apresenta a paulatina formação de um cortejo, que parte dos recantos do sertão em direção à cidade, numa busca que culmina com a chegada a um cemitério. As ações não se consolidam e o tempo se reduz ao tempo do caminhar, do nada em direção ao nada, num movimento que, aos poucos, descobre-se tratar-se de uma viagem de "descobrimento", em busca do próprio país. De maneira alegórica e carnavalizada, o cortejo reúne figuras grotescas, que reprocessam a cultura brasileira e cinematográfica, a partir da ruptura e da ironia agonizante. Em termos de ação, os personagens inexistem, levando a um "eterno recomeçar da estaca zero" (Ferreira, 30/7/1970). A tensão da caminhada é mantida pelos saltos, brigas, gestos de desespero, arrotos e pela histérica profusão de vozes. Em termos da construção do espaço, o relato aproxima-se da experiência dos personagens de três maneiras: a) alguns planos-ponto-de-vista na forma de travellings, pontualmente no início da história representando a caminhada de um personagem que matará o próprio pai, e no encerramento do filme, com um movimento rasante entre as lápides de um cemitério, impregnado pela subjetividade da voz over que narra os créditos finais; $b$ ) a existência de longos planos gerais, estáticos, que apresentam o cortejo chegando ou desaparecendo por terrenos abandonados; $\mathrm{c}$ ) alguns travellings que interagem com os personagens, perdendo-se entre as agitações desesperadas, ou então, assumindo o nervosismo daqueles que se contorcem pelas picadas de terra.

No cortejo de Orgia, Paulo Emilio Salles Gomes vê uma espécie de "cosmogonia brasileira" (Gomes, 27/4/1973), que reprocessa a cultura popular urbana a partir de novas raízes. De fato, a busca pelo país evoca o próprio imaginário do descobrimento, presente na cinematografia brasileira, especialmente entre os anos 1964-74. Alguns filmes do período propõem uma visão antiutópica da descoberta da América, com a radicalização da identificação entre civilização e barbárie. "Acentua-se o lado abismal da peregrinação: esta reúne desgarrados sem fim racional, sem destino; é movimento em direção à desintegração e à derrota" (Xavier, 1999: 165). No caso de Orgia, retoma-se o momento de contato entre a cultura europeia e a cultura ameríndia a partir da ideia de "sifilização", que é ironicamente apontada como a grande contribuição europeia para a América. Assim, temos a figura física de um cortejo em busca do país, experimentado pelos personagens na chave de uma orgia carnavalesca sifilítica, que une civilização e barbárie.

166 ALCEU - n.33 - jul./dez. 2016 
Hitler III mundo (1968), de Agrippino de Paula, enfatiza o desespero e a tortura, a partir do trajeto de um ditador e de heróis ironizados. A estrutura, em blocos narrativos, funciona como uma espécie de mosaico de sequências, agregando ações não-concluídas. As ambientações, as formas de atuação, as sonoridades e os corpos dos personagens são constantemente deslocados e reagrupados; isso se dá a partir de um mecanismo de colagem, em diálogo com as experiências de mixagem, realizadas por Agrippino junto ao grupo Sonda, experimento de criação teatral em colaboração com sua esposa Maria Esther Stockler (Paula, 05/1981). Em Hitler III mundo, os elementos colados, bem como as disjunções suscitadas, contribuem para a construção de uma atmosfera lunática e de autoritarismo. A perambulação propriamente dita assume a forma de um voo rasante pelo terceiro mundo, marcado pela apropriação neurótica e infernal de elementos da cultura americana. A marcha de um grotesco Samurai, de quimono branco, pelas ruas enlameadas de uma favela, é apresentada por um longo travelling reverso. O movimento associa o desespero e a ironia às figuras de autoridade, tomadas como autômatos da conspiração de direita, ou dejetos da indústria cultural. Em termos gerais, portanto, temos o voo rasante sobre o terceiro mundo, aderindo à colagem/mixagem de fragmentos; sendo os protagonistas tomados pelo desespero e a impotência, na qualidade de fragmentos pop de um poder imperialista.

\section{Perambulações proféticas}

Definição geral: subdivisão das perambulações pedestres; deslocamentos entre campo e cidade, tendo entre suas figuras as ambiguidades entre devoção religiosa e presença alienante da cultura industrial. As experiências dos personagens em meio à multidão, na qualidade de artistas ambulantes ou pedintes, levando-se em conta as decorrentes mesclas entre documental e ficcional, colaboram nesta chave de perambulação. Entre os filmes realizados nas imediações da Boca do Lixo, alguns evocam figuras proféticas, tendo como grandes representantes os filmes de José Mojica Marins e de Maurice Capovilla. ${ }^{5}$

Em O profeta da fome (1969), de Capovilla, e Finis hominis (1971), de Mojica, ganha destaque a figura de Zé do Caixão como profeta mambembe e subdesenvolvido. Seu trajeto volta-se à cidade, dando continuidade irônica à religiosidade rural, presente nas figuras proféticas de filmes como Deus e o diabo na terra do sol (1964), de Glauber Rocha, ou Proezas de Satanás na vila de leva e traz (1967), de Paulo Gil Soares. Nos filmes de Mojica e Capovilla, o ludibrio religioso e a alienação promovida pela indústria cultural são colocados lado a lado; em ambos os filmes, a ironia do desfecho final rebate-se sobre o trajeto realizado, reafirmando o pessimismo e a falta de saídas, diante do processo brasileiro de modernização.

Em O profeta da fome (1969), o faquir Ali Khan realiza uma trajetória por paisagens disformes e mambembes, partindo do campo à cidade. Trata-se de uma parábola 
sobre o subdesenvolvimento brasileiro e latino-americano, buscando flertes com "Uma estética da fome" (1965), de Glauber Rocha. A atuação de José Mojica Marins, na figura de um artista que usa a fome como inspiração e meio de subexistência, evoca diálogos com o universo dos gibis, do circo-teatro e de um humor pautado pelo terror kitsch. Ao longo do trajeto do faquir, a fome é apresentada como situação física e como uma forma de ilusão e ludíbrio do povo, que é frequentemente ironizada. De astro de circo mambembe à sua transformação em objeto-mercadoria que termina num lixão, o trajeto de Ali Khan ironiza o crescimento econômico desigual, aproximando-se do Cinema Marginal em sua dimensão de "passeio pela disformidade" (Xavier, 2001a: 76). O relato mescla uma estilização mambembe a la Mojica e um olhar documental atento às faces e costumes locais. É o caso da autocrucificação farsesca, realizada pelo personagem rodeado pelas faces de camponeses, tomados em planos documentais. Este traço foi visto por José Carlos Avellar como uma "ligação íntima entre imagens reais e absurdas (...) uma abordagem que culmina num retrato desordenado, desigual e incompleto feito por quem vive o problema" (Avellar, s.d.). Nos momentos de perambulação pedestre, percebem-se tais oscilações. Entre elas figuram: um cortejo fúnebre, composto por figuras grotescas e medievais, tomadas a partir de travellings e planos quase documentais; uma longa peregrinação, por florestas e terrenos descampados, narrada por um cancioneiro em tonalidades épicas; ou o movimento de romeiros bolivianos, caminhando em multidão em direção a uma caverna, em plano documental, comentado por uma voz over eloquente.

Em Finis hominis (1971), o profeta é um homem nu, que aparece nas águas da praia de Santos e depois se desloca para São Paulo, realizando ao longo de sua trajetória milagres e benfeitorias sarcásticas. Apesar de muitas das sequências serem internas, o filme apresenta uma variação de figurações do ator-personagem diante das massas de seguidores e transeuntes. Com maior tendência ficcional, o filme apresenta variações em torno da figura do pastor lunático seguido por seus adeptos, sejam eles atores, figurantes, transeuntes curiosos ou imagens recostadas de outros filmes. No final, a verdadeira identidade é revelada: trata-se de um doente mental, que havia fugido de um dos sanatórios da cidade. O trajeto realizado, assim, ironiza a crença num profeta lunático e no poder ludibriante dos meios de comunicação em massa.

Para ambas as presenças de Mojica nota-se uma perambulação afinada com a peregrinação de trupes circenses e artistas populares. O protagonista, por sua vez, coloca-se em estado de profecia sarcástica, vislumbrando desmistificações, a partir da união entre o consumo, a devoção religiosa e a loucura. Ao longo dos anos 1970, a perambulação profética terá uma variação nos filmes subterrâneos de Ozualdo Candeias. Especialmente em O Candinho (1976), onde a peregrinação para a cidade em busca de Deus culmina com o desengano, a partir de uma narrativa fundada na interação do personagem com transeuntes, bem como em figuras circulares e na sugestão de um estado de alienação religiosa.

168 ALCEU - n.33 - jul./dez. 2016 


\section{Perambulação em sintonia com o descompasso social}

Definição geral: tipo de perambulação pensada para a obra de um cineasta em particular, Ozualdo Candeias, que pela riqueza e variedade dos deslocamentos, em termos físicos, coteja perambulações automotivas e perambulações pedestres. Em termos temáticos, a atenção aos excluídos coloca-se como contraimagem do desenvolvimento econômico; em termos de estilo, as incorporações de formas narrativas do cinema clássico, somadas às referências cinematográficas brasileiras, sugerem diferentes tipos de ambiguidade.

O cinema de Ozualdo Candeias lida com automóveis e seres que percorrem um mundo em si deslocado, caracterizado pela ambiguidade espacial, a violência e a desclassificação social. Nele identificamos os influxos entre nacional e estrangeiro, entre o rural e o urbano, somados a um olhar cuja temática se desloca, voltando-se à pobreza. Nota-se uma perambulação em sintonia com o descompasso social, que enfatiza setores socialmente excluídos da população, formados por migrantes, prostitutas, pedintes, ambulantes e o subproletariado urbano. Os deslocamentos, sejam eles pedestres ou automotivos, colocam-se como figura de uma violência social mais ampla, denunciando a falácia do crescimento econômico propagandeado pelo governo militar e incorporando o abismo social como regra. Apesar de abordarmos aqui apenas o primeiro longa, $A$ margem, a perambulação em sintonia com o descompasso social se apresentará em diversos dos filmes realizados pelo cineasta entre os anos 1960-90. ${ }^{6}$

No ano de 1967, A margem traz à luz o espaço e a sociabilidade das várzeas, que há muito funcionaram como locais de chegada e de moradia para os migrantes que chegavam à cidade; locais cheios de meandros, sujeitos às enchentes. Neste filme, que se coloca como marco inicial do Cinema Marginal, notamos alguns traços narrativos que seriam posteriormente depurados ao longo dos anos 1970-80. Entre eles: a não-ancoragem dos personagens, que inclui a marginalização em relação à sociedade civil e a impossibilidade de contatos duradouros, com reflexos sobre a construção temática e estilística dos filmes (Gamo, 2000); a ambiguidade do estilo, presente na construção dos espaços, dos sons e dos corpos (Uchoa, 2013); bem como a união entre o abjeto e o sublime (Ramos, 1987). Jean-Claude Bernardet chamará atenção à perambulação em "zonas limítrofes de deterioração", às relações que não se consolidam entre os personagens, ao andar a esmo à espera de algo vago e indeterminado, bem como a "uma pulsação de vida mínima em ambientes degradados (...)" (Bernardet, 2002: 33). Na história de dois casais que aguardam a morte às margens do Tietê, culminado em uma salvação sublime e redentora, a perambulação não está somente nos constantes deslocamentos dos corpos e automóveis que rimam com uma canoa à deriva. O ritmo dos deslocamentos dos corpos e da montagem, a composição fotográfica privilegiando diagonais em profundidade, o constante trânsito por uma ponte, as estranhezas da união entre o grotesco das 
paisagens em ruínas e o sublime da trilha sonora e das composições formais, todas estas tendências reverberam sobre a construção da perambulação. Há, porém, uma figura de estilo bastante particular na estrutura geral do filme: tudo se dá a partir de uma troca sucessiva de olhares entre os personagens, constituindo aquilo que Edward Branigan denominou de "planos-ponto-de-vista" (PPV) (Branigan, 2005).

Trata-se de uma construção relativamente complexa e madura do cinema clássico, que é recontextualizada por Candeias, para a representação de uma população varziana de deserdados. A incorporação da cultura estrangeira é assim usada para a representação do descompasso social, a partir de um descompasso de estilo, entre o formalismo visual e o grotesco da paisagem, que se desdobra numa espécie de perambulação existencial dos explorados. Figura física: a variação dos planos-ponto-de-vista somadas a interações particulares entre grotesco e sublime. Situação das personagens: perambulação existencial; situação mítica das almas após a morte aguardando redenção.

\section{Considerações finais}

Abordamos aqui a perambulação enquanto fenômeno narrativo que, no contexto do Cinema Marginal, desdobra-se em práticas espaciais que se colocam como índices do mal-estar de personagens ante ao mundo. Neste sentido, colaboramos com quatro portas de entrada para futuras análises comparativas. O trato com as imagens, por sua vez, sugere a criação de instrumentos particulares para identificar: as variações dos travellings; as relações estabelecidas entre câmera e corpos em deslocamento; as motivações, destinos e configurações das jornadas; o lugar ocupado pela perambulação no âmbito da lógica narrativa geral de cada filme; bem como as contaminações entre a construção da perambulação e a situação de crise dos personagens ante ao mundo.

Trata-se de fenômenos narrativos, que podem ser tomados como sintomas sociais de um processo de modernização excludente. Somam-se a este prognóstico, a união de fragmentos culturais, unindo o rural e o urbano, o nacional e o importado, bem como referenciais cinematográficos pop, mambembes ou clássicos em diferentes matizes. No Cinema Marginal, sob o viés da perambulação, a colagem tropicalista adquire diferentes nuances de rebeldia e de desespero. Enquanto gesto que escancara o abismo e a deglutição do diverso, tais deslocamentos físicos e culturais podem ser colocados ao lado de conceitos das ciências sociais, formulados para descrever os disparates da modernização brasileira. Assim, Fernando Novais e Cardoso de Mello (1998), pensarão no período militar como a consecução de um capitalismo plutocrático, que tornou o Brasil uma das sociedades mais desiguais do período, unindo expansão acelerada e compressão dos salários. Francisco de Oliveira, por sua vez, identificará a exclusão e a ampliação das desigualdades como elementos vitais da expansão capitalista da época, que posteriormente se desdobraria na figura de 
um "ornitorrinco", uma sociedade altamente industrializada e urbanizada, porém dependente do capital financeiro e com poucos avanços para os extratos pobres (Oliveira, 2003: 133). Na teoria urbana, Marta Grostein, associará o padrão periférico de expansão urbana à criação de um espaço dual, dividido entre a cidade formal, onde se tem a presença do poder público, e a cidade informal, caracterizada pela ilegalidade e pela não-urbanidade (Grostein, 2001). As teorias aqui referidas, que poderiam ser somadas a outras sobre o período, cada uma a seu modo implicam na descrição de deslocamentos, entre diferentes instâncias: o legal e o ilegal; o centro e a periferia; o nacional e o estrangeiro; o campo e a cidade; o moderno e o arcaico; a industrialização e a exclusão social. Ao apresentarem figuras de deslocamento onde as origens e os pontos de chegada tornam-se absurdos e rarefeitos, os modos de perambulação aqui debatidos parecem reverberar e posicionar-se ante a fenômenos sociais e culturais mais amplos, próprios à modernização excludente.

Fábio Raddi Uchôa

Professor da Universidade Federal de São Carlos (UFSCar) raddiuchoa@gmail.com

Recebido em agosto de 2015.

Aceito em novembro de 2015.

\section{Notas}

1. Esse artigo aprofunda um projeto mais amplo de pesquisa, sobre a perambulação no cinema moderno brasileiro, que teve início na minha trajetória de mestrado. Sobre esse tema, ver o primeiro capítulo de meu doutoramento, intitulado "Perambulação, silêncio e erotismo nos filmes de Ozualdo Candeias" (2013). Ver também o artigo "Anotações sobre a perambulação automotiva, o Cinema Marginal e $A$ opção ou as rosas da estrada." RUA - Revista Universitária do Audiovisual, São Carlos, 2014, que aplica alguns destes aportes teóricos a um estudo de caso.

2. Neste trabalho, adota-se a nomenclatura "perambulação" para não se limitar aos possíveis pesos e significados carregados pelo termo em francês ("deambulation"). 3. Alguns filmes do Cinema Marginal com presença, significativa ou apenas em passagem pontual, de perambulações automotivas: Olho por olho (1966) e BangBang (1971) de Andrea Tonacci; O bandido da Luz Vermelha (1968), A mulher de todos (1969), Sem essa Aranha (1970) e Abismu (1977) de Rogério Sganzerla; Caveira my friend (1970) de Álvaro Guimarães; Os monstros de Babaloo (1970) de Elyseu Visconti; Sagrada família (1970) de Sylvio Lana; Aopção ou As rosas da estrada (1981) de Ozualdo Candeias; O anjo nasceu (1968), de Julio Bressane, neste último caso, sendo o plano final do filme uma perambulação automotiva às avessas.

4. Alguns filmes do Cinema Marginal com presença, significativa ou apenas em passagem pontual, de perambulações pedestres: Documentário (1966) e Copacabana 
mon amour (1970) de Rogério Sganzerla; Gamal, o delírio do sexo (1969) de João Batista de Andrade; Hitler III mundo (1968) de José Agrippino de Paula; Orgia ou o Homem que deu cria (1970) de Silvério Trevisan; A margem (1967), Zézero (1974) e O Candinho (1976) de Ozualdo Candeias.

5. Exemplos de filmes do Cinema Marginal com a presença da perambulação profética: O profeta da fome (1969) de Maurice Capovilla, Finis Hominis (1971) de José Mojica Marins e O Candinho (1976) de Ozualdo Candeias. Alguns casos onde a tendência profética é totalmente encampada pela presença da cultura de massas: Ofilho da televisão (1969) de João Batista de Andrade; Zézero (1974) de Ozualdo Candeias.

6. Filmes de Ozualdo Candeias com a presença marcante ou pontual da perambulação em sintonia com o descompasso social: A margem (1967), Caçada sangrenta (1974), Zézero (1974), O Candinho (1976), Aopção ou As rosas da estrada (1978-81). Posteriores do contexto do Cinema Marginal: Manelão, o caçador de orelhas (1981), As bellas da Billings (1986), O vigilante (1992).

\section{Referências}

ABREU, Nuno Cesar. Boca do Lixo: cinema e classes populares. Campinas: Ed. da Unicamp, 2006. AVELLAR, José Carlos. O cinema dilacerado. Rio de Janeiro: Alhambra, 1986.

O absurdo nosso de cada dia. Rio de Janeiro, Jornal do Brasil, s.d.

BAZIN, André. Qu'est-ce que le cinéma? Paris: Ed. du Cerf, 1985.

BENTES, Ivana. Multitropicalismo, cine-sensação e dispositivos teóricos. In: BASUALDO, Carlos (Org.). Tropicália - uma revolução na cultura brasileira. São Paulo: Cosac Naify, 2007. p. 99-128.

BERNARDET, J-C. Jean-Claude Bernardet. In: Ozualdo R. Candeias. São Paulo: CCBB, 2002. p. 33.

2001. p. 12-15.

Cinema Marginal? In: Cinema Marginal e suas fronteiras. São Paulo: CCBB,

. O vôo dos anjos: Bressane, Sganzerla. São Paulo: Editora Brasiliense, 1991.

BRANIGAN, Edward. O plano-ponto-de-vista. In: RAMOS, Fernão Pessoa (Org.) Teoria contemporânea do cinema, volume II. São Paulo: Editora Senac. p. 251-275.

CALLEGARO, João. Nasce o cinema cafajeste: Ana. In: As libertinas - Três histórias de amor e sexo, folheto promocional do filme As libertinas, 1968.

DELEUZE, Gilles. A imagem-movimento. São Paulo: Brasiliense, 1985.

DOUCHET, J. Revistas e homens. In: OLIVEIRA, Luiz Miguel (Org.) Nouvelle Vague. Lisboa: Cinemateca Portuguesa/ Museu do cinema, 1999. p. 111-126. O corpo. In: OLIVEIRA, Luis Miguel (Org.). Nouvelle Vague. Lisboa: Cinemateca Portuguesa/ Museu do cinema, 1999b.

FAVARETTO, C. Tropicália, alegria, alegria. São Paulo: Kairós, 1979.

FERREIRA, J. Trevisan deixa sangrar. São Paulo Shimbun. 30 julho 1970.

GAMO, A. C. Aves sem rumo: a transitoriedade no cinema de Ozualdo Candeias. 2000. Dissertação (Mestrado) - Unicamp, Campinas, 2000.

GOMES, Paulo Emilio S. Cinema: trajetória no subdesenvolvimento. Rio de Janeiro: Paz e Terra, 1980.

172 ALCEU - n.33 - jul./dez. 2016 
. Por que não deixam esse cortejo seguir seu caminho? Jornal da Tarde, São Paulo, 27 abril 1973.

GROSTEIN, Marta Dora. Metrópole e expansão urbana. São Paulo em Perspectiva, vol.15, n.1, jan./ mar. 2001. p.13-19.

MELLO, João Manuel Cardoso de e NOVAIS, Fernando A. Capitalismo tardio e sociabilidade moderna. In: NOVAIS, F. A. e SCHWARCZ, L. M. História da vida privada no Brasil. vol. 4 São Paulo: Cia. das Letras, 1998. p. 560-657.

OLIVEIRA, Francisco de. Crítica à razão dualista. São Paulo: Boitempo, 2003.

PASOLINI, Pier Paolo. Empirismo eretico. Milano: Garzanti, 1972.

PAULA, José Agrippino de. Rito do amor selvagem. Arte em Revista, São Paulo, Ano 3, n. 5, maio 1981. p. 95-96.

RAMOS, Fernão. Cinema Marginal (1968/1973). São Paulo: Brasiliense, 1987.

RAMOS, Guiomar. Um cinema brasileiro antropofágico? São Paulo: Annablume, 2009.

ROCHA, Glauber. Uma estética da fome. Revista Civilização Brasileira, Rio de Janeiro, n. 3, julho de 1965.

SCHWARZ, Roberto. Cultura e Política 1964-69. In: O pai de família e outros estudos. São Paulo: Paz e Terra, 1992. p. 61-92.

SGANZERLA, Rogério. Corpo mais alma. In: Por um cinema sem limite. Rio de Janeiro: Azougue Editorial, 2001. p. 88-96.

STAM, Robert. Para além do terceiro cinema: estéticas do hibridismo. In: LOPES, D. e FRANÇA, A. (Orgs.) Cinema, globalização e interculturalidade. Ed. Unochapecó: Chapecó, 2010. p. 111-136.

UCHOA, Fábio Raddi. Perambulação, silêncio e erotismo nos filmes de Ozualdo Candeias (196783). Tese (Doutorado em Ciências da Comunicação) - ECA/USP, 2013.

VIEIRA, João Luiz. Cinema brasileiro marginal: humor, paródia e chanchada às avessas. In: A invenção do Cinema Marginal, Curso da Cinemateca do MAM-RJ, 2007, p. 13-19.

XAVIER, Ismail. Indagações em torno de Eduardo Coutinho e seu diálogo com a tradição moderna. Cinemais, Rio de Janeiro, n. 36, out.-dez. 2003. . O cinema brasileiro moderno. São Paulo: Paz e Terra, 2001a.

. O Cinema Marginal revisitado ou o avesso dos anos 90. In: Cinema Marginal e

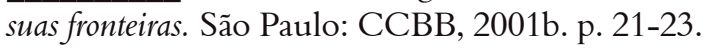

. Eldorado como inferno - cinema novo, pós-cinema e as apropriações do ima-

ginário do descobrimento. Revista sexta-feira, São Paulo, n. 3, 1999. . Alegorias do subdesenvolvimento. São Paulo: Brasiliense, 1993. 


\section{Resumo}

Para definir os traços da perambulação no Cinema Marginal, este artigo articula definições teóricas, a contextualização artístico-cinematográfica e o mapeamento de um grupo de filmes, tomados a partir de suas formulações físicas, temáticas e quanto à experiência das personagens, dividindo-os em quatro chaves: perambulações automotivas, perambulações pedestres, perambulações proféticas e perambulação em sintonia com o descompasso social.

\section{Palavras-chave}

Cinema brasileiro moderno. Cinema Marginal. Perambulação.

\section{Abstract}

Traits of perambulation in Uderground Cinema

To defining the perambulation traits of Underground Brazilian cinema, this article articulates theoretical definitions, the artistic-cinematographic context and the mapping of a group of films, seen in their physical and thematic formulations, and also in the characters experience, dividing them into four keys: automotive perambulations, pedestrian perambulations, prophetic perambulations and the perambulation in tune with the social gap.

\section{Keywords}

Modern Brazilian cinema. Underground Cinema. Perambulation. 